\title{
First report of Giardia duodenalis infection in bamboo rats
}

\author{
Xun $\mathrm{Ma}^{\dagger}$, Yi Wang ${ }^{\dagger}$, Hui-Jun Zhang, Hao-Xian Wu and Guang-Hui Zhao ${ }^{*}$
}

\begin{abstract}
Background: The zoonotic parasite, Giardia duodenalis (syns. G. lamblia and G. intestinalis), has been widely reported in humans and animals, including rodents. The bamboo rat, a rodent species belonged to the subfamily Rhizomyinae, is farmed in China because of its medicinal and edible values. However, no information of $G$. duodenalis infection was available in bamboo rats prior to the present study. Here, the prevalence and genetic diversity of $G$. duodenalis in bamboo rats from Hunan Province of China were investigated.

Results: Of 480 faecal samples collected from six farms located in four cities (Wugang, Chenzhou, Huaihua and Jishou) of Hunan Province, 52 (10.8\%) were positive for G. duodenalis infection by using a nested PCR approach targeting the beta giardin $(b g)$ gene. Significant differences $(P<0.01)$ in prevalence were found among different age groups and geographical localities, and among different farms in Wugang city. Sequence analysis revealed existence of the zoonotic assemblage B and genetic diversity of $G$. duodenalis in these animals. Multilocus genotyping analysis also indicated broad genetic diversity of assemblage $B$ isolates in these bamboo rats.

Conclusions: This is the first report of the infection and genetic variations of $G$. duodenalis in bamboo rats. These findings will provide basic data for implementing effective strategies to control giardiasis in bamboo rats.
\end{abstract}

Keywords: Giardia duodenalis, Prevalence, Bamboo rat, Hunan Province

\section{Background}

Giardia duodenalis (syns. G. lamblia and G. intestinalis) is a common zoonotic protozoan that inhabits the gastrointestinal tracts of animals and humans [1-3]. Giardiasis, caused by G. duodenalis, is an important diarrheal disease concerning both public and veterinary health worldwide $[4,5]$. In recent decades, G. duodenalis infection has been widely reported in domestic (e.g. goats, pigs, cats, rabbits, dogs and calves) and wild animals (e.g. chipmunks, chinchillas, red foxes, lizards, aquatic birds, boars and rhesus macaque) in Asia, Europe, Australia, North America and Africa [6-19], and a wide distribution and high prevalence of up to $100 \%$ in some studies have been reported [20,21]. Although the infection is commonly asymptomatic or self-limiting in immunocompetent hosts [22, 23], watery diarrhea and other significant clinical impacts due to G. duodenalis infection could be observed in young, undernourished,

\footnotetext{
* Correspondence: zgh083@nwsuaf.edu.cn

${ }^{\dagger}$ Xun Ma and Yi Wang contributed equally to this work.

College of Veterinary Medicine, Northwest A\&F University, 22 Xinong Road, Yangling 712100, People's Republic of China
}

or immunocomprised individuals [24, 25]. Furthermore, dormant and long-lasting infectious cysts excreted from hosts can pollute food, water and the environment, causing food-borne and water-borne outbreaks for humans and animals $[26,27]$.

The bamboo rat (Rhizomys sinensis), a rodent species belonging to the subfamily Rhizomyinae, is widely distributed in southern Asia, i.e. southern China, India, Myanmar, northern Vietnam and Thailand [28, 29]. Because of the high protein content, low fat and cholesterol of bamboo rat meat [30], the medicinal and edible values of this animal are favored by people [30]. Since the 1990s, the artificial breeding of bamboo rats began and was rapidly developed [31]. In 2011, over 30 million bamboo rats were farmed in China [32], and the demand for meat of bamboo rats is increasing at an annual rate of $3 \%$ [31]. However, due to changes in habitats and food sources, various pathogens have been reported in bamboo rats $[28,29,33,34]$, and infections of these pathogens could seriously affect the health and economic significance of these animals $[35,36]$. Furthermore, the transmission risk to people of some zoonotic pathogens

(c) The Author(s). 2018 Open Access This article is distributed under the terms of the Creative Commons Attribution 4.0 International License (http://creativecommons.org/licenses/by/4.0/), which permits unrestricted use, distribution, and 
(e.g. Cryptosporidium spp. [34], Penicilliosis marneffei [29], Escherichia coli [33], Trichinella spp.) in these animals should also not be neglected [37]. Although the prevalence of $G$. duodenalis in bamboo rats was, until now, unknown, the presence of this parasite in other rodents (e.g. rats, mice, rabbits, chipmunks, chinchillas, guinea pigs, beavers) has been reported in China, Romania, Laos, America, Germany, Austria, Denmark, Hungary, Finland, France, Italy, Luxembourg, the Netherlands, Norway, Poland, Portugal and Sweden, with a prevalence of $1.9-83.0 \%$ [9, 13, 14, 36, 38-42]. Among them, high prevalence was detected in chinchillas (55.7\%) from Romania [14], chinchillas (61.4\%) from European countries [42] and mice (83\%) from Germany [40]. Of eight assemblages (A-H) reported in animals and humans [22, 40, 43], assemblage $\mathrm{G}$ has been detected in rats and mice [36], and some animal-specific $(\mathrm{C}-\mathrm{H})$ and zoonotic assemblages (A and $\mathrm{B}$ ) were reported in other rodents, i.e. chinchilla, beaver, muskrat and rabbit $[9,26,44,45]$.

To reveal the infection status of $G$. duodenalis in farmed bamboo rats, the prevalence and assemblages of this parasite in bamboo rats from six farms in four cities of Hunan Province, China, were determined, and the genetic diversity of $G$. duodenalis was also investigated by using the multilocus genotyping technique based on three gene loci [46-48], namely beta giardin (bg), triosephosphate isomerase (tpi) and glutamate dehydrogenase $(g d h)$.

\section{Methods}

\section{Collection of faecal specimens}

From August to October 2017, 480 fresh faecal samples (Additional file 1: Table S1), were collected from seemingly healthy bamboo rats in six farms located in four cities (Wugang, Chenzhou, Huaihua and Jishou) of Hunan Province (Additional file 2: Figure S1), south-central China. Bamboo rats within four age groups (< 6 months; 6-12 months; > 12-24 months; and $>24$ months) were investigated in the present study. Because of similar housing conditions in all examined sampling sites in this study, a fraction of animals were included (Additional file 1: Table S1). Approximately a third of bamboo rats representing each age group were examined in Farms 1-4. Since animals belonging to limited age groups (Additional file 1: Table S1) were raised on Farm 5 and Farm 6, a small number of samples within the existed age groups were collected. A faecal sample from each animal was collected immediately after defecation using disposable plastic bags, marked with the age, date, site and number, then transferred into a $15 \mathrm{ml}$ centrifuge tube with $2.5 \%$ potassium dichromate solution and stored at $4{ }^{\circ} \mathrm{C}$.

\section{Extraction of genomic DNA from faecal samples}

To remove potassium dichromate solution, all faecal specimens of bamboo rats were washed several times using distilled water under centrifugation at $13,000 \times$ rpm for $1 \mathrm{~min}$. Then, the genomic DNA sample was extracted from approximately $300 \mathrm{mg}$ of washed faeces using the commercial E.Z.N.A ${ }^{\oplus}$ Stool DNA Kit (Omega Bio-Tek Inc., Norcross, GA, USA) following the manufacturer's protocol. The extracted DNA samples were stored at $-20{ }^{\circ} \mathrm{C}$ for further analysis.

\section{Nested PCR analysis and sequencing}

The prevalence of $G$. duodenalis in bamboo rats was determined by using a nested PCR targeting the $b g$ gene using primers reported previously [7, 49-51]. The samples positive for the $b g$ gene were further analyzed with nested PCRs of gene loci tpi and $g d h$, respectively [7]. A $25 \mu \mathrm{l}$ PCR mixture was used for PCR amplification, containing $1 \mu$ l genomic DNA (for the primary PCR) or primary amplification product (for the secondary PCR) as the template, $2.5 \mu \mathrm{l} \mathrm{10 \times Ex} \mathrm{Taq}$ buffer $\left(\mathrm{Mg}^{2+}\right.$ free), 2 $\mathrm{mM} \mathrm{MgCl}_{2}, 0.2 \mathrm{mM}$ dNTP mixture, $0.625 \mathrm{U}$ TaKaRa $E x$ Taq (TaKaRa Shuzo Co., Ltd, Dalian, China) and 0.4 $\mu \mathrm{M}$ of each primer. Negative and positive controls were included in each PCR reaction and negative samples were spiked with positive material to investigate whether sample material had been associated with inhibition. The secondary PCR amplicons were analyzed by using $1 \%$ agarose gels electrophoresis with ethidium bromide. The positive secondary amplicons were sent to Sangon Biotech Co. Ltd. (Shanghai, China) for direct sequencing using the secondary PCR primers.

\section{Sequence analysis}

The nucleotide sequences obtained were aligned and edited by using the software Clustal X 1.83 [52]. Then, the corrected sequences were aligned with the reference sequences of $G$. duodenalis within GenBank by using Basic Local Alignment Search Tool (BLAST) of the National Center for Biotechnology Information (NCBI) to identify the assemblages and subtypes.

\section{Statistical analysis}

The differences in prevalence among bamboo rats of different age groups and farms were calculated by using the Chi-square test within the software SPSS 19.0 for Windows (SPSS Inc., Chicago, IL, USA), and the difference was considered statistically significant when $P<$ 0.05 .

\section{Results and discussion}

Giardia duodenalis infection has been reported in humans and a large number of animal hosts worldwide $[8,9,15,47]$. The prevalence has been reported as 1.09- 
$72.4 \%$ in farmed animals (e.g. rabbits, goats, cattle, pigs, dogs, cats, Tibetan sheep and calves), and $3.2-83.0 \%$ in wild rodents (e.g. Apodemus spp., Microtus spp., Myodes spp., house mice, brown rats, Asian house rats, beavers, roof rats and deer mice) [7, 9-12, 36, 38-41, 53-57]. In the present study, this parasite was detected in bamboo rats from Hunan Province of China, and 52 (10.8\%) of 480 samples were positive for $G$. duodenalis infection based on the nested PCR amplification targeting the $b g$ gene. The prevalence of $G$. duodenalis in bamboo rats in this study was well in the range of previous studies in farmed animals and wild rodents. However, significant differences in prevalence $\left(\chi^{2}=59.031, d f=5, P<0.01\right)$ were detected among six farms from four sampling cities, ranging from 0 to $38.2 \%$. The highest prevalence was found on Farm 3 of Wugang city (38.2\%), while no infections were detected on Farm 4 of Chenzhou city and Farm 6 of Jishou city (Table 1). Furthermore, the prevalence was also significantly different $\left(\chi^{2}=28.876, d f=2\right.$, $P<0.01)$ among three farms in Wugang city, with the highest on Farm 3 and lowest on Farm 1 (Table 1). The differences in prevalence among these farms could be due to different feeding and management levels. For example, bamboo rats in Farm 4 from Chenzhou city were mainly fed with concentrate (e.g. corn, wheat) and kept in multilayer vertical cages, which reduced the risks of pathogenic infections. On the other hand, in farms of Wugang city, both fresh bamboo and concentrate were fed to the animals, all of which were reared in wooden fences. Furthermore, different sampling practices may also have contributed to the differences between farms. Samples varying in number were collected from different farms (Table 1), ranging from 15 (Farm 6) to 207 (Farm 1). Different age groups and sample numbers within the same age groups tested (Additional file 1: Table S1) are also possible explanations for differences in prevalence. Additionally, detection procedures and targets are also possible factors affecting the rates of $G$. duodenalis infection. Due to its multiple-copy nature [58], the small subunit ribosomal RNA (SSU rRNA) gene was commonly used as a good marker to detect $G$. duodenalis infection in animals and humans [22, 58, 59]. However, this gene locus cannot effectively identify assemblages and sub-assemblages because of low sequence variability [58]. In the present study, nested PCR targeting the $b g$ gene was used to investigated G. duodenalis infection in bamboo rats. Theoretically, $b g$ is unique to Giardia and has a high degree of sequence diversity for identifying sub-assemblages $[49,50,58]$. However, compared with the $S S U$ rRNA gene locus, the copy number is lower. In addition, nested PCR may not be used to distinguish between infection (cysts being excreted following encystation) and G. duodenalis DNA being excreted due to dead cysts being ingested. Alternatively, although an under-estimation of prevalence may be associated with traditional microscopy [60], morphological methods could reflect the infection intensity and extent of environmental contamination [61-63]. A previous study also established a real-time method using the $b g$ gene to simultaneously evaluate cyst viability and discern zoonotic G. duodenalis assemblages A and B [64]. Therefore, to fully reveal the infection status of $G$. duodenalis in bamboo rats, many methods should be incorporated in future studies.

A significant difference $\left(\chi^{2}=28.298, d f=3, P<0.01\right)$ in prevalence was also observed in bamboo rats of the four age groups in the present study (Table 1). The infection seemingly decreased with age (Table 1), with the highest prevalence $(22.8 \%)$ in animals under six months and the lowest (4.6\%) in animals over 24 months, which

Table 1 Prevalence and factors associated with G. doudenalis infection in bamboo rats in Hunan Province, China

\begin{tabular}{|c|c|c|c|c|c|c|}
\hline \multirow[t]{2}{*}{ Variable } & \multirow[t]{2}{*}{ Category } & \multirow{2}{*}{$\begin{array}{l}\text { No. } \\
\text { examined }\end{array}$} & \multirow{2}{*}{$\begin{array}{l}\text { No. } \\
\text { positive } \\
(\%)\end{array}$} & \multicolumn{3}{|c|}{ Target locus (no. positive) } \\
\hline & & & & $b g$ & tpi & $g d h$ \\
\hline \multirow[t]{5}{*}{ Age } & $<6$ months & 136 & $31(22.8)$ & 31 & 6 & 15 \\
\hline & 6-12 months & 128 & $8(6.3)$ & 8 & 4 & 6 \\
\hline & $>12-24$ months & 151 & $10(6.6)$ & 10 & 1 & 4 \\
\hline & $>24$ months & 65 & $3(4.6)$ & 3 & 1 & 2 \\
\hline & Total & 480 & $52(10.8)$ & 52 & 12 & 27 \\
\hline \multirow[t]{7}{*}{ Location } & Wugang city (Farm 1) & 207 & $19(9.2)$ & 19 & 8 & 15 \\
\hline & Wugang city (Farm 2) & 66 & $9(13.6)$ & 9 & 2 & 3 \\
\hline & Wugang city (Farm 3) & 55 & $21(38.2)$ & 21 & 2 & 9 \\
\hline & Chenzhou city (Farm 4) & 111 & 0 & 0 & 0 & 0 \\
\hline & Huaihua city (Farm 5) & 26 & $3(11.5)$ & 3 & 0 & 0 \\
\hline & Jishou city (Farm 6) & 15 & 0 & 0 & 0 & 0 \\
\hline & Total & 480 & $52(10.8)$ & 52 & 12 & 27 \\
\hline
\end{tabular}


is in concordance to previous studies that indicated that young individuals of humans and animals are prone for Giardia infection [25]. However, investigations in chinchillas [44] and rabbits [65-68] from China, and deer mouse from California central coast of the USA [38] were inconsistent with this common phenomenon. The difference could be caused by different detection technologies, sample numbers, feeding manners, environmental conditions and geographical separation.

Five G. duodenalis assemblages (A, B, D, E and G) have been detected in rodents [14, 36, 42, 45, 66, 69]. In the present study, all G. duodenalis positive samples from bamboo rats were identified as assemblage B. This finding would indicate the fact of simple G. duodenalis population in bamboo rats. This result may also be due to small sampling numbers from limited areas in this study. To address this point, a large number of epidemiological investigations should be implemented in future studies. However, assemblage B could be transmitted zoonotically [70-72] and has a broad host range, including livestock, companion animals, fish, and marine and wild mammals [12, 13, 18, 21, 26, 73, 74]. Furthermore, assemblage $B$ was also detected in some water bodies [45]. Of the two assemblages (A and B) commonly found in humans, assemblage B was identified in over $50 \%$ of Giardia-infected children in some studies $[22,72,75]$. A significant association between diarrhoea and the infection of this assemblage was also reported in children from Havana, Cuba [76]. To address the zoonotic potential of G. duodenalis in bamboo rats in investigated areas of Hunan Province, the infection status of handlers/farmers in the farms should be determined in future studies.

Additionally, although previous studies have indicated that assemblage $\mathrm{B}$ isolates have high genetic polymorphism, double peaks and ambiguity SNPs to hinder the classification of sub-assemblages and subtypes [48], we did not find any ambiguous nucleotides in our study. Of 52 G. duodenalis-positive samples, 52, 12 and 27 were successfully amplified at loci $b g$, tpi and $g d h$, respectively, by using nested PCRs (Table 2). Six polymorphic sites were found at the $b g$ gene locus and six distinct subtypes were identified (Table 2 ), including three known (named as $\mathrm{Ba} 1, \mathrm{Ba} 2$ and $\mathrm{Ba} 3$ ) and three novel (named as $\mathrm{Ba} 4, \mathrm{Ba} 5$ and $\mathrm{Ba} 6$ ) subtypes. The sequences of $\mathrm{Ba} 1, \mathrm{Ba} 2$ and $\mathrm{Ba} 3$ had a $100 \%$ identity to an isolate (KM977640) from chinchillas in China [44], an isolate (KY696836) from Hylobatidae in China [71], and an isolate (KM190805) from humans in Canada [45], respectively, while 99\% identities of three novel subtypes $\mathrm{Ba} 4, \mathrm{Ba} 5$ and $\mathrm{Ba} 6$ were found with the reference sequence KM977640 [44]. Additionally, six subtypes (Bc1-Bc6) and four subtypes (named as $\mathrm{Bb} 1-\mathrm{Bb} 4$ ) were also identified in
Table 2 Substitutions of intra-assemblage B in bg, tpi and gdh sequences

\begin{tabular}{|c|c|c|c|c|c|c|c|}
\hline \multirow{2}{*}{$\begin{array}{l}\text { Subtype }(n) \\
b g\end{array}$} & \multicolumn{6}{|c|}{ Nucleotide positions and substitutions } & \multirow[t]{2}{*}{ GenBank ID } \\
\hline & 60 & 66 & 267 & 294 & 328 & 483 & \\
\hline Ref. sequence & G & $\mathrm{T}$ & C & C & G & C & KM977640 \\
\hline Ba1 (1) & G & $\mathrm{T}$ & C & C & G & C & MH598574 \\
\hline $\mathrm{Ba} 2(25)$ & G & C & C & C & G & C & MH598579 \\
\hline Ba3 (7) & A & $\mathrm{T}$ & C & $\mathrm{T}$ & G & C & MH598575 \\
\hline $\mathrm{Ba} 4(7)$ & G & C & $\mathrm{T}$ & C & G & C & MH598578 \\
\hline Ba5 (11) & G & C & C & C & G & $\mathrm{T}$ & MH598576 \\
\hline Ba6 (1) & G & C & C & C & A & C & MH598577 \\
\hline tpi & 218 & 240 & 282 & 405 & 490 & & \\
\hline Ref. sequence & C & G & C & A & G & & HQ666898 \\
\hline Bb1 (6) & C & G & C & A & G & & MH598587 \\
\hline Bb2 (4) & $\mathrm{T}$ & G & C & G & G & & MH598589 \\
\hline Bb3 (1) & $\mathrm{T}$ & G & C & G & $\mathrm{T}$ & & MH598588 \\
\hline Bb4 (1) & $\mathrm{T}$ & A & $\mathrm{T}$ & G & G & & MH598586 \\
\hline$g d h$ & 192 & 282 & 369 & 396 & 477 & & \\
\hline Ref. sequence & $\mathrm{T}$ & $C$ & A & $\mathrm{T}$ & C & & HM134212 \\
\hline $\mathrm{BC} 1(2)$ & $\mathrm{T}$ & C & A & $\mathrm{T}$ & C & & MH598585 \\
\hline Bc2 (8) & C & C & A & C & C & & MH598582 \\
\hline Bc3 (4) & $\mathrm{T}$ & $C$ & A & C & $\mathrm{T}$ & & MH598583 \\
\hline Bc4 (3) & $\mathrm{T}$ & C & A & C & C & & MH598581 \\
\hline Bc5 (8) & $\mathrm{T}$ & $\mathrm{T}$ & G & C & C & & MH598580 \\
\hline Bc6 (2) & $\mathrm{T}$ & $\mathrm{T}$ & A & C & C & & MH598584 \\
\hline
\end{tabular}

27 gdh-positive samples and 12 tpi-positive samples (Table 2).

\section{Conclusions}

Giardia duodenalis occurs in bamboo rats from Hunan Province of China and the infection was significantly associated with age and farms. Although only one assemblage (B) was identified in bamboo rats in the present study, zoonotic potential and genetic diversity were found. To our knowledge, this is the first report on $G$. duodenalis infection in bamboo rats.

\section{Additional files}

Additional file 1: Table S1. Sampling information in the present study. (DOCX $12 \mathrm{~kb}$ )

Additional file 2: Figure S1. Sampling sites in the present study. (TIF $2527 \mathrm{~kb})$

\section{Abbreviations}

bg: beta giardin; tpi: triosephosphate isomerase; gdh: glutamate dehydrogenase

\section{Acknowledgments}

We are grateful to Guo-Hua Liu, Jun-Ke Song and Sha-Sha Wang for collecting samples. 


\section{Availability of data and materials}

Datasets supporting the conclusions of this article are included within the article. The sequences have been submitted to the GenBank database under the accession numbers MH598574-MH598579 (bg gene), MH598586MH598589 (tpi gene) and MH598580-MH598585 (gdh gene).

\section{Authors' contributions}

GHZ conceived and designed the experiments. HJZ and XM collected the samples. XM and HXW finished the experiment and sequence analyses. XM, YW and GHZ wrote and corrected the manuscript. All authors read and approved the final manuscript

\section{Ethics approval}

The present study meets the requirements of the Guidance of Laboratory Animal Care and Use of Chinese Ministry of Health, China, and was approved by the Research Ethics Committee of Northwest Agriculture and Forestry University. All faecal samples were collected under the farm owner's permission and no bamboo rats were harmed during sampling.

\section{Consent for publication}

Not applicable.

\section{Competing interests}

The authors declare that they have no competing interests.

\section{Publisher's Note}

Springer Nature remains neutral with regard to jurisdictional claims in published maps and institutional affiliations.

\section{Received: 8 July 2018 Accepted: 11 September 2018} Published online: 20 September 2018

\section{References}

1. Thompson RC, Reynoldson JA, Mendis AH. Giardia and giardiasis. Adv Parasitol. 1993:32:71-160.

2. Doglioni C, De Boni M, Cielo R, Laurino L, Pelosio P, Braidotti P, Viale G. Gastric giardiasis. J Clin Pathol. 1992;45:964-7.

3. Olson ME, O'Handley RM, Ralston BJ, McAllister TA, Thompson RC. Update on Cryptosporidium and Giardia infections in cattle. Trends Parasitol. 2004;20: 185-91.

4. Savioli L, Smith H, Thompson A. Giardia and Cryptosporidium join the 'Neglected Diseases Initiative'. Trends Parasitol. 2006;22:203-8.

5. Thompson RC. Giardiasis as a re-emerging infectious disease and its zoonotic potential. Int J Parasitol. 2000:30:1259-67.

6. Utaaker KS, Myhr N, Bajwa RS, Joshi H, Kumar A, Robertson LJ. Goats in the city: prevalence of Giardia duodenalis and Cryptosporidium spp. in extensively reared goats in northern India. Acta Vet Scand. 2017:59:86.

7. Wang SS, Yuan YJ, Yin YL, Hu RS, Song JK, Zhao GH. Prevalence and multilocus genotyping of Giardia duodenalis in pigs of Shaanxi Province, northwestern China. Parasit Vectors. 2017:10:490.

8. Yang R, Ying JL, Monis P, Ryan U. Molecular characterisation of Cryptosporidium and Giardia in cats (Felis catus) in Western Australia. Exp Parasitol. 2015:155:13-8.

9. Zhang X, Qi M, Jing B, Yu F, Wu Y, Chang Y, et al. Molecular characterization of Cryptosporidium spp., Giardia duodenalis, and Enterocytozoon bieneusi in rabbits in Xinjiang, China. J Eukaryot Microbiol. 2018. https://doi.org/10. 1111/jeu.12629.

10. Gil H, Cano L, de Lucio A, Bailo B, de Mingo MH, Cardona GA, et al Detection and molecular diversity of Giardia duodenalis and Cryptosporidium spp. in sheltered dogs and cats in Northern Spain. Infect Genet Evol. 2017;50:62-9.

11. Munoz J, Mayer DC. Toxoplasma gondii and Giardia duodenalis infections in domestic dogs in New York City public parks. Vet J. 2016;211:97-9.

12. Naguib D, El-Gohary AH, Mohamed AA, Roellig DM, Arafat N, Xiao L. Age patterns of Cryptosporidium species and Giardia duodenalis in dairy calves in Egypt. Parasitol Int. 2018:67:736-41.

13. Deng L, Luo R, Liu H, Zhou Z, Li L, Chai Y, et al. First identification and multilocus genotyping of Giardia duodenalis in pet chipmunks (Eutamias asiaticus) in Sichuan Province, southwestern China. Parasit Vectors. 2018;11:199.
14. Gherman CM, Kalmár Z, Györke A, Mircean V. Occurrence of Giardia duodenalis assemblages in farmed long-tailed chinchillas Chinchilla lanigera (Rodentia) from Romania. Parasit Vectors. 2018;11:86.

15. Mateo M, de Mingo MH, de Lucio A, Morales L, Balseiro A, Espí A, et al. Occurrence and molecular genotyping of Giardia duodenalis and Cryptosporidium spp. in wild mesocarnivores in Spain. Vet Parasitol. 2017;235:86-93

16. Reboredo-Fernández A, Ares-Mazás E, Galán P, Cacciò SM, Gómez-Couso H. Detection of zoonotic and livestock-specific assemblages of Giardia duodenalis in free-living wild lizards. Rev Bras Parasitol Vet. 2017;26:395-9.

17. Cano L, de Lucio A, Bailo B, Cardona GA, Muadica AS, Lobo L, Carmena D. Identification and genotyping of Giardia spp. and Cryptosporidium spp. isolates in aquatic birds in the Salburua wetlands, Álava, northern Spain. Vet Parasitol. 2016;221:144-8

18. Li W, Deng L, Wu K, Huang X, Song Y, Su H, et al. Presence of zoonotic Cryptosporidium scrofarum, Giardia duodenalis assemblage A and Enterocytozoon bieneusi genotypes in captive Eurasian wild boars (Sus scrofa) in China: potential for zoonotic transmission. Parasit Vectors. 2017;10:10.

19. Debenham JJ, Tysnes K, Khunger S, Robertson L. Occurrence of Giardia, Cryptosporidium, and Entamoeba in wild rhesus macaques (Macaca mulatta) living in urban and semi-rural North-West India. Int J Parasitol Parasites Wildl. 2017;6:29-34.

20. Ralston BJ, McAllister TA, Olson ME. Prevalence and infection pattern of naturally acquired giardiasis and cryptosporidiosis in range beef calves and their dams. Vet Parasitol. 2003:114:113-22.

21. Bednarska M, Bajer A, Sinski E, Girouard AS, Tamang L, Graczyk TK. Fluorescent in situ hybridization as a tool to retrospectively identify Cryptosporidium parvum and Giardia lamblia in samples from terrestrial mammalian wildlife. Parasitol Res. 2007;100:455-60.

22. Feng Y, Xiao L. Zoonotic potential and molecular epidemiology of Giardia species and giardiasis. Clin Microbiol Rev. 2011;24:110-40.

23. Yason JA, Rivera WL. Genotyping of Giardia duodenalis isolates among residents of slum area in Manila, Philippines. Parasitol Res. 2007;101:681-7.

24. Faubert GM. The immune response to Giardia. Parasitol Today. 1996;12:140-5.

25. Ankarklev J, Jerlström-Hultqvist J, Ringqvist E, Troell K, Svärd SG. Behind the smile: cell biology and disease mechanisms of Giardia species. Nat Rev Microbiol. 2010:8:413-22.

26. Sulaiman IM, Fayer R, Bern C, Gilman RH, Trout JM, Schantz PM, et al. Triosephosphate isomerase gene characterization and potential zoonotic transmission of Giardia duodenalis. Emerg Infect Dis. 2003;9:1444-52.

27. Choy SH, Al-Mekhlafi HM, Mahdy MA, Nasr NN, Sulaiman M, Lim YA, Surin J. Prevalence and associated risk factors of Giardia infection among indigenous communities in rural Malaysia. Sci Rep. 2014:4:6909.

28. Tang HB, Chen F, Rao G, Bai A, Jiang J, Du Y, et al. Characterization of Akabane virus from domestic bamboo rat, southern China. Vet Microbiol. 2017;207:280-5.

29. Cao C, Liang L, Wang W, Luo H, Huang S, Liu D, et al. Common reservoirs for Penicillium marneffei infection in humans and rodents, China. Emerg Infect Dis. 2011;17:209-14.

30. Chen J, Qu X. Economic animal - feeding management and prospects of bamboo rat. Feeding Manage. 2015;6:24-6 (In Chinese).

31. Song $X C$, Yang FH, Xing XM, Yue ZG. The species, value and prospect of artificial breeding of bamboo rat in China. Special Econom Anim Plant. 2009:12:8-10 (In Chinese).

32. Liu J, Tang CH, Zhou DC, Zeng QB. Current situation and countermeasures of bamboo rat in China. J Hunan Environ-Biolog Polytechnic. 2011;17:1-5 (In Chinese).

33. Zhang H, Li K, Wang Y, Rehman MU, Liu Y, Jin J, et al. Investigation and characterization of $\beta$-lactam resistance in Escherichia coli strains isolated from bamboo rats (Rhizomys sinensis) in Zhejiang Province, China. J Vet Med Sci. 2017;79:1633-6.

34. Liu X, Zhou X, Zhong Z, Zuo Z, Shi J, Wang Y, et al. Occurrence of novel and rare subtype families of Cryptosporidium in bamboo rats (Rhizomys sinensis) in China. Vet Parasitol. 2015;207:144-8.

35. Li X, Yang Y, Zhang X, Zhou X, Lu S, Ma L, et al. Isolation of Penicillium marneffei from soil and wild rodents in Guangdong, SE China. Mycopathologia. 2011:172:447-51.

36. Zhao Z, Wang R, Zhao W, Qi M, Zhao J, Zhang L, et al. Genotyping and subtyping of Giardia and Cryptosporidium isolates from commensal rodents in China. Parasitology. 2015;142:800-6. 
37. Yang HM. Studies on epidemiology and control of trichinosis in Yunnan Province. Chin J Parasitol Parasitic Dis. 1991;S1:79-82 (In Chinese).

38. Kilonzo C, Li X, Vodoz T, Xiao C, Chase JA, Jay-Russell MT, et al. Quantitative shedding of multiple genotypes of Cryptosporidium and Giardia by deer mice (Peromyscus maniculatus) in a major agricultural region on the California Central Coast. J Food Prot. 2017:80:819-28.

39. Promkerd $P$, Khoprasert $Y$, Virathavone $P$, Thoummabouth $M$, Sirisak $O$ Jäkel T. Factors explaining the abundance of rodents in the city of Luang Prabang, Lao PDR, as revealed by field and household surveys. Integr Zool. 2008:3:11-20.

40. Helmy YA, Spierling NG, Schmidt S, Rosenfeld UM, Reil D, Imholt C, et al. Occurrence and distribution of Giardia species in wild rodents in Germany. Parasit Vectors. 2018;11:213.

41. Fayer R, Santín M, Trout JM, DeStefano S, Koenen K, Kaur T. Prevalence of Microsporidia, Cryptosporidium spp., and Giardia spp. in beavers (Castor canadensis) in Massachusetts. J Zoo Wildl Med. 2006;37:492-7.

42. Pantchev N, Broglia A, Paoletti B, Globokar Vrhovec M, Bertram A, Nöckler $K$, et al. Occurrence and molecular typing of Giardia isolates in pet rabbits, chinchillas, guinea pigs and ferrets collected in Europe during 2006-2012. Vet Rec. 2014;175:18.

43. Lebbad M, Petersson I, Karlsson L, Botero-Kleiven S, Andersson JO, Svenungsson B, Svärd SG. Multilocus genotyping of human Giardia isolates suggests limited zoonotic transmission and association between assemblage B and flatulence in children. PLoS Negl Trop Dis. 2011;5: e1262.

44. Qi M, Yu F, Li S, Wang H, Luo N, Huang J, Zhang L. Multilocus genotyping of potentially zoonotic Giardia duodenalis in pet chinchillas (Chinchilla lanigera) in China. Vet Parasitol. 2015;208:113-7.

45. Prystajecky N, Tsui CK, Hsiao WW, Uyaguari-Diaz MI, Ho J, Tang P, IsaacRenton J. Giardia spp. are commonly found in mixed assemblages in surface water, as revealed by molecular and whole-genome characterization. Appl Environ Microbiol. 2015;81:4827-34.

46. Cacciò SM, Beck R, Lalle M, Marinculic A, Pozio E. Multilocus genotyping of Giardia duodenalis reveals striking differences between assemblages $A$ and B. Int J Parasitol. 2008;38:1523-31.

47. Huey CS, Mahdy MA, Al-Mekhlafi HM, Nasr NA, Lim YA, Mahmud R, Surin J. Multilocus genotyping of Giardia duodenalis in Malaysia. Infect Genet Evol. 2013:17:269-76

48. Faria CP, Zanini GM, Dias GS, da Silva S, Sousa MDC. New multilocus genotypes of Giardia lamblia human isolates. Infect Genet Evol. 2017;54:128-37.

49. Cacciò SM, De Giacomo M, Pozio E. Sequence analysis of the beta-giardin gene and development of a polymerase chain reaction-restriction fragment length polymorphism assay to genotype Giardia duodenalis cysts from human faecal samples. Int J Parasitol. 2002;32:1023-30.

50. Lalle M, Pozio E, Capelli G, Bruschi F, Crotti D, Cacciò SM. Genetic heterogeneity at the beta-giardin locus among human and animal isolates of Giardia duodenalis and identification of potentially zoonotic subgenotypes. Int J Parasitol. 2005;35:207-13.

51. Azcona-Gutiérrez JM, de Lucio A, Hernández-de-Mingo M, García-García C, Soria-Blanco LM, Morales $L$, et al. Molecular diversity and frequency of the diarrheagenic enteric protozoan Giardia duodenalis and Cryptosporidium spp. in a hospital setting in northern Spain. PLoS One. 2017;12:e0178575.

52. Thompson JD, Gibson TJ, Plewniak F, Jeanmougin F, Higgins DG. The CLUSTAL_X windows interface: flexible strategies for multiple sequence alignment aided by quality analysis tools. Nucleic Acids Res. 1997;25:4876-82.

53. Zhong Z, Tu R, Ou H, Yan G, Dan J, Xiao Q, et al. Occurrence and genetic characterization of Giardia duodenalis and Cryptosporidium spp. from adult goats in Sichuan Province, China. PLoS One. 2018;13:e0199325.

54. Wang $X$, Cai $M$, Jiang $W$, Wang $Y$, Jin $Y$, Li N, et al. High genetic diversity of Giardia duodenalis assemblage $E$ in pre-weaned dairy calves in Shanghai, China, revealed by multilocus genotyping. Parasitol Res. 2017;116:2101-10.

55. Wu Y, Chang Y, Chen Y, Zhang X, Li D, Zheng S, et al. Occurrence and molecular characterization of Cryptosporidium spp., Giardia duodenalis, and Enterocytozoon bieneusi from Tibetan sheep in Gansu, China. Infect Genet Evol. 2018;64:46-51.

56. Li F, Wang H, Zhang Z, Li J, Wang C, Zhao J, et al. Prevalence and molecular characterization of Cryptosporidium spp. and Giardia duodenalis in dairy cattle in Beijing, China. Vet Parasitol. 2016;219:61-5.

57. Gillhuber J, Pallant L, Ash A, Thompson RC, Pfister K, Scheuerle MC. Molecular identification of zoonotic and livestock-specific Giardia-species in faecal samples of calves in Southern Germany. Parasit Vectors. 2013;6:346.
58. Koehler AV, Jex AR, Haydon SR, Stevens MA, Gasser RB. Giardia/giardiasis - a perspective on diagnostic and analytical tools. Biotechnol Adv. 2014;32:280-9.

59. Weiss JB, van Keulen H, Nash TE. Classification of subgroups of Giardia lamblia based upon ribosomal RNA gene sequence using the polymerase chain reaction. Mol Biochem Parasitol. 1992;54:73-86.

60. Dixon BR, Parenteau M, Martineau C, Fournier J. A comparison of conventional microscopy, immunofluorescence microscopy and flow cytometry in the detection of Giardia lamblia cysts in beaver fecal samples. I Immunol Methods. 1997;202:27-33.

61. Elsafi SH, Al-Maqati TN, Hussein MI, Adam AA, Hassan MM, Al Zahrani EM, Comparison of microscopy, rapid immunoassay, and molecular techniques for the detection of Giardia lamblia and Cryptosporidium parvum. Parasitol Res. 2013;112:1641-6.

62. Behr MA, Kokoskin E, Gyorkos TW, Cédilotte L, Faubert GM, Maclean JD. Laboratory diagnosis for Giardia lamblia infection: a comparison of microscopy, coprodiagnosis and serology. Can J Infect Dis. 1997;8:33-8.

63. Weitzel T, Dittrich S, Möhl I, Adusu E, Jelinek T. Evaluation of seven commercial antigen detection tests for Giardia and Cryptosporidium in stool samples. Clin Microbiol Infect. 2006;12:656-9.

64. Baque RH, Gilliam AO, Robles LD, Jakubowski W, Slifko TR. A real-time RTPCR method to detect viable Giardia lamblia cysts in environmental waters. Water Res. 2011:45:3175-84.

65. Jiang J, Ma JG, Zhang NZ, Xu P, Hou G, Zhao Q, Zhang XX. Prevalence and risk factors of Giardia duodenalis in domestic rabbbits (Oryctolagus cuniculus) in Jilin and Liaoning Province, northeastern China. J Infect Public Health. 2018;11:723-6.

66. Qi M, Xi J, Li J, Wang H, Ning C, Zhang L. Prevalence of zoonotic Giardia duodenalis assemblage $\mathrm{B}$ and first identification of assemblage $\mathrm{E}$ in rabbit fecal samples isolates from central China. J Eukaryot Microbiol. 2015;62:810-4.

67. Xi JW, Zhang KF, Qi M, Wu GQ, Xu LN, Jian FC, et al. Investigation of the infection of Giardia duodenalis in large-scale farms of rabbits in Henan Province. Anim Husb Vet Med. 2011;43:78-79 (In Chinese).

68. Shi K, Ren XP, Wang Q, Qi M, An CX, Chen LF, et al. Investigation of the intestinal parasitic infection in rabbits in partial areas of Henan Province. Anim Husb Vet Med. 2010;42:68-70 (In Chinese)

69. Liu A, Yang F, Shen Y, Zhang W, Wang R, Zhao W, et al. Genetic analysis of the $\mathrm{Gdh}$ and $\mathrm{Bg}$ genes of animal-derived Giardia duodenalis isolates in northeastern China and evaluation of zoonotic transmission potential. PLoS One. 2014;9:e95291.

70. Cacciò SM, Lalle M, Svärd SG. Host specificity in the Giardia duodenalis species complex. Infect Genet Evol. 2017. https://doi.org/10.1016/j.meegid. 2017.12.001.

71. Zhong Z, Tian Y, Li W, Huang X, Deng L, Cao S, et al. Multilocus genotyping of Giardia duodenalis in captive non-human primates in Sichuan and Guizhou provinces, southwestern China. PLoS One. 2017;12:e0184913.

72. Fahmy HM, El-Serougi AO, El Deeb HK, Hussein HM, Abou-Seri HM, Klotz C, et al. Giardia duodenalis assemblages in Egyptian children with diarrhea. Eur J Clin Microbiol Infect Dis. 2015:34:1573-81.

73. Ryan U, Cacciò SM. Zoonotic potential of Giardia. Int J Parasitol. 2013; 43:943-56.

74. Yang R, Reid A, Lymbery A, Ryan U. Identification of zoonotic Giardia genotypes in fish. Int J Parasitol. 2010:40:779-85.

75. Mohammed Mahdy AK, Surin J, Wan KL, Mohd-Adnan A, Al-Mekhlafi MS, Lim YA. Giardia intestinalis genotypes: Risk factors and correlation with clinical symptoms. Acta Trop. 2009:112:67-70.

76. Jerez Puebla LE, Núñez FA, Santos LP, Rivero LR, Silva IM, Valdés LA, et al. Molecular analysis of Giardia duodenalis isolates from symptomatic and asymptomatic children from La Habana, Cuba. Parasite Epidemiol Control. 2017;2:105-13. 